\title{
Correction to: Minimizing a Wireless Passive LC-Tank Sensor to Monitor Bladder Pressure: A Simulation Study
}

\author{
Jacob Melgaard ${ }^{1}$ (1) . Johannes J. Struijk ${ }^{1}$ Nico J. M. Rijkhoff ${ }^{1}$
}

Published online: 9 February 2018

(c) Taiwanese Society of Biomedical Engineering 2018

\section{Correction to: J. Med. Biol. Eng. (2017) 37:800-809 https://doi.org/10.1007/s40846-017-0244-2}

The article "Minimizing a Wireless Passive LC-Tank Sensor to Monitor Bladder Pressure: A Simulation Study", written by Jacob Melgaard, Johannes J. Struijk, Nico J. M. Rijkhoff was originally published Online First without open access. After publication in volume [37], issue [6], page [800-809] the author decided to opt for Open Choice and to make the article an open access publication. Therefore, the copyright of the article has been changed to (C) The Author(s) [2018] and the article is forthwith distributed under the terms of the Creative Commons Attribution 4.0 International License (http://creativecommons.org/licenses/by/4.0/), which permits use, duplication, adaptation, distribution and reproduction in any medium or format, as long as you give appropriate credit to the original author(s) and the source, provide a link to the Creative Commons license, and indicate if changes were made.

The original article can be found online at https://doi.org/10.1007/ s40846-017-0244-2.

Jacob Melgaard

jm@hst.aau.dk

1 Department of Health Science and Technology, The Faculty of Medicine, Aalborg University, Fredrik Bajers Vej 7, 9220 Aalborg Ø, Denmark 